\title{
Hypopituitarism and Deep Vein Thrombosis
}

\author{
Jameel Ummar ${ }^{1}$, Ganesh H. K², Uday B. Nayak ${ }^{3}$ \\ ${ }^{1}$ PG Resident, Department of General Medicine, A.J. Institute of Medical Sciences, Mangalore, ${ }^{2}$ Consultant Endocrinologist, \\ Department of Endocrinology, A.J. Institute of Medical Sciences, Mangalore, ${ }^{3}$ Professor, Department of General Medicine, \\ A.J. Institute of Medical Sciences, Mangalore, India
}

Corresponding author: Jameel Ummar, PG Resident, Department of General Medicine, A.J. Institute of Medical Sciences, Mangalore, India

DOI: http://dx.doi.org/10.21276/ijcmsr.2019.4.2.18

How to cite this article: Jameel Ummar, Ganesh H. K, Uday B. Nayak. Hypopituitarism and deep vein thrombosis. International Journal of Contemporary Medicine Surgery and Radiology. 2019;4(2):B80-B82.

\section{A B S T R A C T}

Introduction: Deep vein thrombosis is a manifestation of venous thromboembolism. Patients with hypopituitarism may have increased risk of thrombosis, the exact mechanism being hypopituitarism leading to hypothyroidism being a hypercoagulable state.

Case reports: In this study, we have studied three cases of hypopituitarism causing deep vein thrombosis. Case 1: Mrs.B, 62-year-old post-menopausal lady had behavioural alterations. On evaluation, she was diagnosed to have Empty Sella Syndrome. Case 2: Mr.H, 32-year-old male who had underwent Transsphenoidal surgery for Craniopharyngioma, presenting with hypopituitarism. Case 3: Mrs.S, 42-year-old lady known case of Paralytic poliomyelitis of the left lower limb complained of severe fatiguability and amenorrhea for one year, with history of oral contraceptive pills. On evaluation, Investigations revealed hypopituitarism.

Conclusion: In consideration with the patient's clinical findings and laboratory investigations, it has been found that patients with hypopituitarism are more prone for Deep Vein Thrombosis because of hypothyroidism, Diabetes Insipidus, Oestrogen component of Hormone Replacement Therapy and glucocorticoid use. Physicians treating hypopituitarism should consider Deep Vein Thrombosis as a complication.

Keywords: Hypopituitarism, Deep Vein Thrombosis, Thromboembolism, Hypothyroidism

\section{INTRODUCTION}

Inadequate production of anterior pituitary hormones leads to hypopituitarism. Deep vein thrombosis is a manifestation of venous thromboembolism. Patients with hypopituitarism may have increased risk of thrombosis, the exact mechanism being hypopituitarism leading to hypothyroidism being a hypercoagulable state ${ }^{1}$

Virchow's triad describes three factors for thrombosis that is venous stasis, secondly activation of coagulation pathway and thirdly venous damage. Risk factors for venous thromboembolism include varicose veins, immobility (bed rest $>4$ days), previous deep vein thrombosis or pulmonary thromboembolism, Estrogen therapy including Hormone replacement Therapy, Plasminogen deficiency, past history of neurosurgery, trauma and polycythaemia Vera. ${ }^{2}$

Putative mechanisms by which thyroid hormone deficiency may influence coagulation proteins are ill defined, yet it is most likely that it does so by thyroid hormone receptormediated regulation of gene transcription at the hepatic or endothelial cell level, or both. Other hypotheses include indirect effects mediated through $\beta$-adrenergic receptor function. ${ }^{3}$

\section{CASE REPORTS}

Case 1: Mrs.B, 62-year-old post-menopausal lady had behavioural alterations for which she was on treatment with a psychiatrist. She was admitted for severe drowsiness and on investigations was found to have hyponatremia, which was corrected with hypertonic saline. She was admitted multiple episodes of hyponatremia. Evaluation revealed Central hypothyroidism, Reduced Free T4, Above normal TSH, Low cortisol $\{<1 \mathrm{mcg} / \mathrm{dl}\}$ and low gonadotrophin levels suggesting hypopituitarism, MRI Brain showed Empty Sella Syndrome. On History, she had lactation failure and amenorrhea after the last child birth. Hence, she was diagnosed with Sheehan's Syndrome and started on Thyroxine and T. Prednisolone. She improved with medications. After one month of treatment, she developed swelling of left lower limb swelling. Venous doppler showed Deep Vein Thrombosis, with extension to Inferior Vena Cava. IVC Filter was placed and started on Warfarin Therapy.

Case 2: Mr.H, 32-year-old male underwent Transsphenoidal surgery for Craniopharyngioma. He was on replacement therapy with Thyroxine, Prednisolone, Testosterone and desmopressin. He discontinued the medications for 2 weeks. Following which he was admitted with severe hypernatremia. He was also found to have swelling of the right lower limb, Venous doppler revealed Deep vein thrombosis.

Case 3: Mrs.S, 42-year-old lady known case of Paralytic poliomyelitis of the left lower limb complained of severe 
fatiguability and amenorrhea for one year. On evaluation, investigations revealed hypopituitarism. Hyponatremia, Serum cortisol $2.1 \mathrm{mcg} / \mathrm{dL}$, Free T4: 0.6, TSH: Normal, FSH: Low and LH: low. MRI Brain showed no abnormality. She was started on thyroxine, Prednisolone and oral contraceptive pills. After 2 months of treatment, she was admitted to the Medical Intensive Care Unit with severe breathlessness, on evaluation, she was diagnosed to have Deep Vein Thrombosis with Pulmonary Thromboembolism. She was managed with Low Molecular Weight Heparin (LMWH), warfarin and put on Inferior Vena Cava Filter.

\section{Reports}

\begin{tabular}{|l|c|c|c|c|}
\hline Values & Mrs. B & Mr. H & Mrs. S & Reference \\
\hline Sodium & 123 & 128 & 121 & $135-145 \mathrm{mg} / \mathrm{dL}$ \\
\hline T4 & 5.0 & 4.5 & 5.6 & $>4.5 \mathrm{mcg} / \mathrm{dL}$ \\
\hline TSH & 5.5 & 3.1 & 1.8 & $0.5-4.5 \mathrm{U} / \mathrm{L}$ \\
\hline Prolactin & 4.8 & 7.0 & 3.5 & $5-10.2 \mathrm{ng} / \mathrm{dL}$ \\
\hline INR & 3.99 & 2.14 & 1.98 & $0.5-1.0$ \\
\hline Cortisol & $<1$ & 10 & 2.1 & $>18 \mathrm{mcg} / \mathrm{dL}$ \\
\hline FSH & 0.9 & 1.9 & 1.0 & $2-6.6 \mathrm{U} / \mathrm{L}$ \\
\hline LH & 0.5 & 2.2 & 0.25 & $3-12 \mathrm{U} / \mathrm{L}$ \\
\hline
\end{tabular}

\section{DISCUSSION}

In consideration with the patient's clinical findings and laboratory investigations, it has been found that patients with hypopituitarism have higher chances of developing deep vein thrombosis. Alteration in coagulation system is well- studied in case of both overt and subclinical hypothyroidism. These patients have hypercoagulable state contributed by increased bleeding time, and APTT. Data regarding the increased propensity towards thrombosis in patients with hypopituitarism is inconsistent. Johansson et al., compared 20 hypopituitary adults with 20 age matched controls and demonstrated higher plasma fibrinogen and plasminogen activator inhibitor-1 suggestive of defective fibrinolytic system. [4] It may be related either to their problem with coagulation system or underling autoimmunity. Hyponatremia is mediated by increased release of antidiuretic hormone $(\mathrm{ADH})$ which results in water retention and a reduction in the plasma sodium concentration. ${ }^{4}$

Glucocorticoids are potent anti-inflammatory drugs. Experimental studies show that glucocorticoids increase levels of clotting factors and fibrinogen. ${ }^{5}$

Hypothyroidism was defined in patients with raised TSH and low free T4/T3 levels. The principal abnormality in the patient with normal fluid intake appears to be the inability to maximally suppress antidiuretic hormone. This is most likely due to reduced cardiac output in this disorder, which can lead to the release of antidiuretic hormone via the carotid sinus baroreceptors. The glomerular filtration is also decreased in hypothyroidism. This can directly diminish free water excretion by diminishing water delivery to the diluting segments. Decreased delivery may be particularly important in those cases in which hyponatremia develop despite appropriate suppression of $\mathrm{ADH}$ release. ${ }^{6}$ In our case study, Mrs.B had developed hyponatrimea secondary to hypopituitarism. Prednisolone therapy itself must have increased the likelihood of deep vein thrombosis.

The association between VTE and cancer has been recognized and currently represents the second leading cause of death in cancer patients. The risk ofVTE in cancer patients is frequently multifactorial including inducing vascular endothelial cell damage and releasing pro-coagulants that activate the clotting cascade. Furthermore, the hypercoagulable state is frequently exacerbated by chemotherapeutic drugs, placement of central venous catheters, and patient inactivity. Patients undergoing craniotomy by itself has also been suggested to increase the risk of VTEs. The main contributing factor for the deveopment of DeepVein Thrombosis is linked to the duration of the neurosurgerical procedure associated with the removalofcraniopharyngioma and the insertion of central venous catheter. A case report published in Japanese Journal of Neurosurgery also highlited the strong association of DVT, Pulmonary Embolism and cranipharyngioma. ${ }^{7,8,10}$ As in this case report, $\mathrm{Mr}$.H having undergone neurosurgical procedure for craniopharyngioma had developed DVT post procedure which can be well co-related with other studies as well.

The association of Oral Contraceptives and Deep Vein Thrombosis is well known since the 1960's. The relative risk for thrombosis in patients who take COCs is three- to fivefold higher compared with that of nonusers. Oestrogen is associated with numerous prothrombotic alterations in proteins involved in coagulation. COC users have several procoagulant changes in blood proteins, including increased levels of factors II, VII, VIII, and X and fibrinogen, decreased levels of antithrombin and protein $\mathrm{S}$, and acquired resistance to activated protein C. ${ }^{12}$ First-pass hepatic metabolism of oral oestrogen leads to increased hepatic synthesis of factor VII, factor X, and fibrinogen. ${ }^{9}$ In our case, Mrs. S was on oral contraceptive medications for hypopituitarism which has increased her chances for Deep Vein Thrombosis.

\section{CONCLUSION}

Patients with hypopituitarism are more prone for Deep Vein Thrombosis because of hypothyroidism, Diabetes Insipidus, Oestrogen component of Hormone Replacement Therapy and glucocorticoid use. Physicians treating hypopituitarism should consider Deep Vein Thrombosis as a complication.

\section{REFERENCES}

1. Mir S.A, Masoodi S.R, Wani I.A et al. Deep vein thrombosis in a patient of Sheehan's syndrome: Autoimmunity or hypercoagulabilty. Indian J Endocrinol Metab. 2013; 17(Suppl1): S105-S106.

2. Rumbaut RE, Thiagarajan P.San Rafael (CA): Morgan \& Claypool Life Sciences; 2010.

3. UpToDate- clinical evidences based online resources.

4. Oelkers W. Hyponatremia and Inappropriate secretion of vasopressin (antidiuretic hormone) in patients with hypopituitarism. N Eng1 J Med 1989; 321(3):492.

5. Use of Glucocorticoids and Risk of venous thromboembolism.May 2013.JAMA Intern Med. 2013;173(9):743-752.

6. Col C.D.S. Katoch A Col K.S. Brar B, Brajesh Singh, Evaluation of thyroid and adrenal functions in patients with hyponatremia. Medical journal armed forces india 
2013;69(2):237 e240

7. Shindo.A, Matsumoto.Y, Okada.M et al. A case of Deep Vein Thrombosis,Pulmonary Embolism and Non occlusive mesenteric ischemia after removal of recurrent craniopharyngioma 2003;12(5):47-52.

8. Chaichana.K.L, Pendleton.C, Jackson.C et al. Deep venous thrombosis and pulmonary embolisms in adult patients undergoing craniotomy for brain tumors. Neurol Res. 2013;35(2): 206-211.

9. Trenor.C.C, Richard J. Chung, Alan D. Michelson et al. Hormonal Contraception and Thrombotic Risk: A Multidisciplinary Approach. Pediatrics. 2011 Feb; 127(2): 347-357.

10. Harrisons Principles of Internal Medicine $19^{\text {th }}$ Edition.

\section{Source of Support: Nil; Conflict of Interest: None}

Submitted: 16-04-2019; Accepted: 11-05-2019; Published online: 03-06-2019 